\title{
Human Footprint on the Global Environment: Threats to Sustainability
}

\author{
edited by Eugene A. Rosa, Andreas Diekmann, Thomas Dietz, and Carlo Jaeger \\ Cambridge, MA: MIT Press, 2010 \\ ISBN 978-0-262-01315-4 \\ Hardcover, C\$44.60, 328 pp.
}

\author{
Reviewed by Helmut Burkhardt \\ Ryerson University, Toronto \\ helmut.burkhardt@bell.net
}

The preface says that ecological research so far has been mainly done from a physical and biological sciences perspective; sociologists started late in contributing to this field. It is the aim of this book to update the reader on the state of ecological research from a social science point of view. Unfortunately, this otherwise thorough and carefully researched work suffers from the proverbial tunnel vision of experts. How could the authors and editors forget the threat of nuclear weapons to sustainability?

The first chapter, written by Eugene Rosa and Thomas Dietz, is on Global Transformations; it gives an excellent summary of the state and the processes occurring in the global ecosystem. The basics of human impact on the environment, i.e., over-population, consumerism, and inappropriate technology, are duly covered. A list of issues, including those requiring the attention of social sciences, is given together with a long list of references. Reading this first chapter is made difficult by the extensive use of acronyms, whose meaning must be found hidden in the text.

Human-created risks of global scope are the objects of the second chapter, authored by Ulrich Beck. In a realistic, scientific, and technology-oriented worldview (first modernity), these manufactured risks are seen as negative side effects of rational efforts to sustain civilization. Seen through the lens of constructivist social science (second modernity), these manufactured risks give reason to doubt the benefits of technology and the authority of science, and place more emphasis on individuals and societies to construct a more sustainable future. Without it being explicitly stated, it can be concluded that both world views are contributing to change. The social discourse is necessary because the evolution cannot be predicted accurately by ecological science, and ecological science is needed because without it the constructivists may create a pie in the sky.

The bulk of chapter 2 gives a detailed account of the messy realism-constructivism debate that is raging today. The climate change debate is used to illustrate the situation. The believers in climate science warn of the catastrophic consequences if no corrective measures are taken. The sceptics take the constructivist point of view; they point to the uncertainties in climate science, the damage created by inappropriate technology; they plead for the creation of institutions to deal with the global risks due to climate change. Traditional national governments do not have the mandate or the ability to cope with global nature of the threats, hence sub-political actors (IUN, WWF, Greenpeace, etc.) appear on the scene to tackle the global issues. The proposed governance through transnational networks does not seem to be a way out of the messy discourse. In the end, the cosmopolitan state is proposed as a way out of the chaotic efforts to cope with global problems. That looks like a good idea, in fact. We already have the global juridical arm - the International Court of Justice and the International Criminal Court; the UN General Assembly could well serve as a creator of globally valid legislation; and a properly reformed Security Council equipped with a UN Constabulary could serve as the executive arm of global governance.

Chapter 3 is entitled "Human Driving Forces of Global Change: Dominant Perspective." The authors are Thomas Dietz, Eugene A. Rosa, and Richard York. The entity of analysis is discussed in an introduction to the chapter. All levels — the individual, community, national, regional, and global—are seen as relevant and ought to be analyzed. However, only the national level has received attention in theory and in empirical studies. Hence, the chapter's scope is limited to this level by the availability of literature. The purpose of this chapter is to provide a survey of the inter- 
connectedness of the ecological and the social sciences, while in reality they are separated by dramatic paradigm differences between the natural sciences and the social sciences.

The basic drivers of global environmental change are well covered by a thorough discussion of the Ehrlich and Holdren environmental impact formula I=PAT, containing population, per capita consumption and technology applied. However, the quoted critiques of the IPAT formula are not fair. IPAT offers an accurate description of instantaneous processes in the ecosystem of a given state. It does not claim to predict the future of an ecosystem. The difficulty of predicting the future of complex systems is reflected in the rest of the chapter, which tries to get, at least qualitatively, a handle on the non-linearity, trade-offs, feedbacks, etc.

Barry Commoner is rightly given credit for emphasizing the importance of the technology factor and the role of social justice and politics on global environmental change. However, he ought to have been criticized for neglecting the population and per capita consumption factors in the IPAT equation. Julian Simon is unapologetically discussed as representing the social sciences aspect. One would expect a bit more criticism of his "unabashed anthropocentrism." A more reasonable "enlightened anthropocentrism" would at least acknowledge the need for integrating the natural sciences and the social sciences paradigms.

The consequences of Alan Schnaiberg's views are interesting: capitalism is built on the treadmill of production and profits, which require a growing economy. As this is the primary cause of environmental deterioration, the only way to curb this problem is to overthrow this economic order and to install a no-growth system. The hope that increased production is leading to less ecological damage and environmental Kuznets curves has been shattered by observations in several growing economies in the recent past.

Neither post-materialist values nor structural changes seem to stop the driving forces of environmental change. In the end, it seems that only institutional changes and effective global governance can help. Responsive political institutions seem essential for environmental protection.

Chapter 5 is written by Oran R. Young. It is entitled "The Effectiveness of International Environmental Regimes." The international environmental regime is conceptualized as a set of rules and procedures that govern the interaction of participants. These regimes can be bilateral, multilateral, or even global. They emerge as declarations or as ratified treaties from some environmental problems that require attention. Currently there are several hundred such regimes in force. Can that be effective? That is the question this chapter intends to answer. It turns out that this is a difficult task. After clarifying the semantics of "output," "outcome," and "impact," of a regime, and after analyzing several more concepts with great care, no clear definition of effectiveness of international environmental regimes emerges. It is concluded that these international regimes do matter. They can serve to settle conflicts without global environmental governance. However, the existing knowledge needs to be consolidated and expanded in order to get new insights on the determinants of effectiveness. The courageous effort in this chapter is still insufficient to give a valid assessment of the functioning of the highly complex system of international environmental regimes. Establishing global governance with legislative, juridical, and executive powers might be a more effective way to go.

"Uncommon Ground: Critical Perspectives on Common Property" is the title of chapter 6, written by Bonnie J. McCay and Svein Jentoft. The tragedy of the open access commons and the critiques of this model are characterized as "thin," while social embeddedness in a community and state regulation are presented as "thicker" analysis. The socially embedded member of a functioning community has additional guidelines for action beyond the basic one of following self-interest. The state, too, has a role to play in preventing the tragedy of the commons by regulating access. In the "thicker" theory, a tragedy of the commons can be interpreted as community failure or a misfiring of state regulations. There is no word in this chapter on the need for global social and state regulation of access to the global commons in today's globalized world.

The title of chapter 7 is "Vulnerability of Coupled Human-Ecological Systems to Global Environmental Change." The authors are Jeanne X. Kasperson, Roger E. Kasperson, and B.L. Turner II. A summary of current research on the vulnerability of human-ecological systems is presented. However, all the existing approaches are context- or case-specific, and hence the acquired knowledge from empirical studies is "distressingly noncumulative." A more systematic analysis of vulnerability issues is urgently needed. In the end, an integrative conceptual framework is presented, which is applicable to all situations, and can be used as a guideline for the study of specific cases.

Chapter 8 is written by Eugene A. Rosa and Thomas Dietz. It is entitled "Human Dimensions of Coupled Human-Natural Systems: A Look Backward and Forward.” It offers a short survey of what has been presented, and recommends priorities for future research. 